\title{
Atmospheric Moisture and Cloud Cover Characteristics Forecast by AMPS*
}

\author{
RYAN L. FOGT ${ }^{+}$AND DAVID H. BROMWICH \\ Polar Meteorology Group, Byrd Polar Research Center, and Atmospheric Sciences Program, Department of Geography, The Ohio \\ State University, Columbus, Ohio
}

(Manuscript received 26 October 2006, in final form 15 August 2007)

\begin{abstract}
Antarctic Mesoscale Prediction System (AMPS) forecasts of atmospheric moisture and cloud fraction (CF) are compared with observations at McMurdo and Amundsen-Scott South Pole station (hereafter, South Pole station) in Antarctica. Overall, it is found that the model produces excessive moisture at both sites in the mid- to upper troposphere because of a weaker vertical decrease of moisture in AMPS than observed. Correlations with observations suggest AMPS does a reasonable job of capturing the low-level moisture variability at McMurdo and the upper-level moisture variability at South Pole station. The model underpredicts the cloud cover at both locations, but changes to the AMPS empirical CF algorithm remove this negative bias by more than doubling the weight given to the cloud ice path.

A "pseudosatellite" product based on the microphysical quantities of cloud ice and cloud liquid water within AMPS is preliminarily evaluated against Defense Meteorological Satellite Program (DMSP) imagery during summer to examine the broader performance of cloud variability in AMPS. These comparisons reveal that the model predicts high-level cloud cover and movement with fidelity, which explains the good agreement between the modified CF algorithm and the observed CF. However, this product also demonstrates deficiencies in capturing low-level cloudiness over cold ice surfaces primarily related to insufficient supercooled liquid water produced by the microphysics scheme, which also reduces the CF correlation with observations.

The results suggest that AMPS predicts the overall CF amount and high cloud variability notably well, making it a reliable tool for longer-term climate studies of these fields in Antarctica.
\end{abstract}

\section{Introduction}

Some of the most intense synoptic-scale cyclones on earth occur in the Antarctic circumpolar trough, a low pressure belt that surrounds the Antarctic continent. When these storms enter the Ross Sea embayment, they often impact the weather at McMurdo station, the hub for the United States Antarctic Program (USAP). Serving as the largest station in Antarctica, McMurdo is very active during the summer field season (OctoberFebruary) with intercontinental flights from New Zealand as well as intracontinental operations to the

\footnotetext{
* Byrd Polar Research Center Contribution Number 1360.

+ Current affiliation: NOAA/Earth System Research Laboratory, Physical Sciences Division, Boulder, Colorado.
}

Corresponding author address: Ryan L. Fogt, NOAA/Earth System Research Laboratory, Physical Sciences Division, 325 Broadway R/PSD, Boulder, CO 80305.

E-mail: ryan.fogt@noaa.gov
Amundsen-Scott South Pole station (hereafter, South Pole station) and remote field camps in the Dry Valleys and surrounding locations. Because of these operations, accurate weather forecasts are a necessity to ensure the safety of the scientists and support staff as well as the efficiency of USAP operations.

To aid in this regard, the Polar Meteorology Group of the Byrd Polar Research Center at The Ohio State University optimized the fifth-generation Pennsylvania State University-National Center for Atmospheric Research (PSU-NCAR) Mesoscale Model (MM5) for the polar ice sheets (Bromwich et al. 2001; Cassano et al. 2001; more information available online at http:// polarmet.mps.ohio-state.edu). This model, the Polar MM5 (PMM5), is run by NCAR's Mesoscale and Microscale Meteorology (MMM) division in real time to support USAP operations, but also has been used by other nations to support their Antarctic operations. Additionally, the model has played an important role in emergency evacuations from the continent (Monaghan et al. 2003) and the ice-trapped Magdalena Oldendorf 
(Powers et al. 2003). This experimental project between NCAR and Ohio State is known as the Antarctic Mesoscale Prediction System (AMPS; Powers et al. 2003). (The model products are available online in real time at http://www.mmm.ucar.edu/rt/mm5/amps/.)

Many validation studies have been conducted using PMM5 in Antarctica. A study by Guo et al. (2003) shows that the model performs with reasonable skill on diurnal to annual time scales, while a recent study by Bromwich et al. (2005) shows that many variables from the model correlate well $(r>0.9)$ with available observations, particularly in the free atmosphere above the influence of the complex topography. Although AMPS was primarily designed to support USAP operations, it has also been used to better understand the climatology of the region. Monaghan et al. (2005) demonstrate for the first time that the main source of moisture at McMurdo is from synoptic cyclones passing to the northeast and east of Ross Island. Additionally, their study finds that the low precipitation in the McMurdo Dry Valleys is a precipitation shadow effect, and that cloud cover and precipitation are largely determined by the amount of open water in the Ross Sea.

A common link between the validation and research studies is the lower skill of the cloud prediction. Guo et al. (2003) demonstrate that the lowest skill on the annual time scale is the deficient cloud cover in the interior of Antarctica. Bromwich et al. (2005) further show that the cloud fraction is predicted with lower skill than state variables such as pressure, temperature, and wind speed and direction. Therefore, the objective of this paper is to further evaluate the moist processes in AMPS (including the prediction of cloud), find sources for model error, and offer suggestions for model improvement. From a forecasting standpoint, the moist processes in the form of cloud ceilings below flight minima, heavy snow, and dense fog are the phenomena that most strongly impact the USAP operations. From a scientific standpoint, little is understood regarding the variability and occurrence of these phenomena in Antarctica, especially in the dynamically unique environment represented by the McMurdo area. To the authors' knowledge, this is the first time a mesoscale numerical weather prediction model has been evaluated with regard to cloud characteristics (coverage, cloud liquid water and ice content, etc.) in Antarctica. Thus, an evaluation of the AMPS's performance in this area will lead to a better understanding of these complex processes and the extent to which the model accurately captures their variability.

The paper is laid out as follows. Section 2 describes in more detail the data and methods, including the PMM5 configuration. Section 3 evaluates the model perfor-

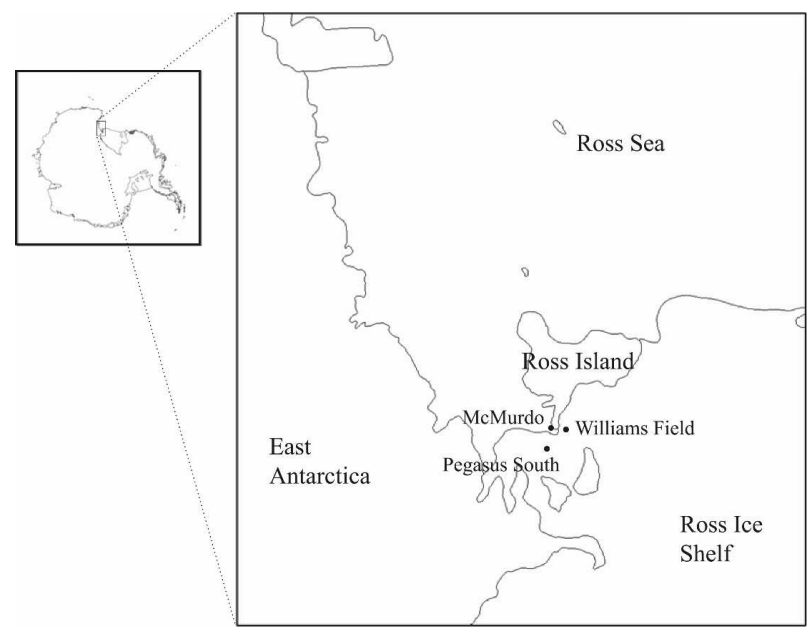

FIG. 1. The AMPS 3.3-km domain.

mance for the McMurdo region, and is complemented by a similar evaluation at South Pole station in section 4 , which represents the model performance over the interior of the continent. A new AMPS product that displays predicted cloud cover and movement is described and preliminarily evaluated in Section 5. A summary and overall evaluation of the performance of AMPS moist processes is offered in Section 6.

\section{Data and methods}

\section{a. AMPS data and configuration}

The moist processes in AMPS are examined for the period December 2003-February 2005. During this period, AMPS consisted of six domains: 1) a 90-km horizontal resolution domain covering half of the Southern Hemisphere, 2) a 30-km domain over the Antarctic continent, 3) a 10-km grid covering the western Ross Sea, 4) a 3.3-km domain covering the immediate Ross Island region, 5) a 10-km grid encompassing the South Pole station, and 6) a 10-km domain enclosing the Antarctic Peninsula. Bromwich et al. (2005) examine the differences between the 10- and 3.3-km domains in the Ross Island region and find that the higher-resolution domain provides improved prediction of the nearsurface winds, largely due to the better representation of the region's complex topography with the higherresolution grid. Because moisture variability and its transport by the wind are also dependent upon topography, the validations performed here for McMurdo are conducted using the higher-resolution $3.3-\mathrm{km}$ grid (Fig. 1), while evaluations for South Pole station are made with the $30-\mathrm{km}$ grid. It is noteworthy that in late 2005, the horizontal resolution of the AMPS suite of grids was increased to $60,20,6.6$, and $2.2 \mathrm{~km}$, respec- 
tively, from the $90,30,10$, and $3.3-\mathrm{km}$ configurations described above. Thus, the validation period represents the last full field seasons and the encompassed winter before this resolution change, with the further benefit that the data from this period are readily available via the AMPS online archive maintained by the Polar Meteorology Group at The Ohio State University (available online at http://polarmet.mps.ohio-state.edu/ PolarMet/ampsdb.html). Only data from the 0000 UTC initializations are compared, with forecast hours 6-36 and 6-72 retained for the 3.3- and 30-km grids, respectively.

\section{b. Observational data}

Cloud fraction (CF) observations in octas for McMurdo, Pegasus South runway, and Williams Field (see Fig. 1 for locations) were obtained from the University of Wisconsin's Antarctic Meteorological Research Center (AMRC; information online at http://amrc.ssec. wisc.edu). The observed $\mathrm{CF}$ in octas was converted to decimal values to compare with the modeled $\mathrm{CF}$ values from AMPS. Although this conversion introduces some error, the impact of this conversion was not assessed and thought to be small. The McMurdo data are available every $3 \mathrm{~h}$ during the summer field seasons and every $6 \mathrm{~h}$ during the winter seasons, while at the runways data are available at hourly intervals during the summer seasons only. In particular, at Pegasus the data are available only when the runway is used operationally, that is, during the early and late summer; during the middle of the field season (October-December), the Ice Runway (which is closer to McMurdo) is used. These CF observations are manual ground reports from trained weather observers working for the USAP. Although observer bias may also introduce error into these observed values, all weather observers are trained using the same guidelines and reference criteria, which implies this bias is minimal. This is verified since simultaneous CF observations taken by different observers at these locations are in good agreement, thereby making the observations reliable enough to be used for model validation.

The radiosonde relative humidity record for McMurdo was also obtained from the AMRC as well as from the British Antarctic Survey (BAS; information online at http://www.antarctica.ac.uk/met/metlog/). The record is available twice daily (0000 and 1200 UTC) during the summer field season and once daily (0000 UTC) during the polar winter. All data for South Pole station were obtained from the BAS, with surface data at 6-hourly intervals and radiosonde data available as at McMurdo.
Radiosonde humidity measurements are subject to three main sources of error, but the magnitudes of these errors vary depending on the radiosonde type (Miloshevich et al. 2001, 2004, 2006). During the validation period considered here, both McMurdo and South Pole station used the most recent version of Vaisala radiosondes, the RS92. These radiosondes have faster sensor response times than their predecessors, the RS80-H and RS80-A (Paukkunen et al. 2001), so temperaturedependent corrections have not been established for this equipment (Miloshevich et al. 2004). Additionally, the RS92 radiosondes undergo a process called "regeneration," where the sensor is heated during launch preparations, effectively recovering the original calibration accuracy and removing any contaminations arising from the packaging (Hirvensalo et al. 2003). Miloshevich et al. (2006) show that relative humidity measurements from RS92 radiosondes not corrected for the time-lag error have close agreement $(<10 \%$ difference) throughout the midlatitude troposphere, even at temperatures as cold as $-70^{\circ} \mathrm{C}$, compared to the University of Colorado Cryogenic Frostpoint Hygrometer $(\mathrm{CFH})$, an instrument that has a known accuracy of $1 \%-3 \%$ throughout the troposphere. Further, their study demonstrates that applying the time-lag correction to the RS92 can lead to an overestimation of the relative humidity in the upper troposphere. Thus, timelag corrections are not done in this study, but the Atmospheric Infrared Sounder (AIRS) Water Vapor Experiment (AWEX) empirical calibration correction as discussed by Miloshevich et al. (2006) is performed on all the soundings, leading to adjustments of $\sim 3 \%$ in the measured relative humidity, with maximum changes up to $5 \%$. The corrected measurements without the time-lag corrections are deemed accurate enough for the comparisons made here with modeled relative humidity values from AMPS.

\section{AMPS validation in the McMurdo region}

\section{a. Relative humidity}

Here, the AWEX-corrected relative humidity measurements from the McMurdo radiosonde record are compared to AMPS predictions at most mandatory levels up to $100 \mathrm{hPa}$. Figure 2 displays the relative humidity with respect to ice $\left(\mathrm{rh}_{\text {ice }}\right)$ correlation (Fig. 2a) and bias (model minus observations; Fig. 2b). The statistics here provide insight beyond that of Bromwich et al. (2005) as they consider levels above $500 \mathrm{hPa}$ and below $850 \mathrm{hPa}$, observations that are corrected for measurement error, and are separated for various forecast hours. Interestingly, Fig. 2 demonstrates a peak in the 

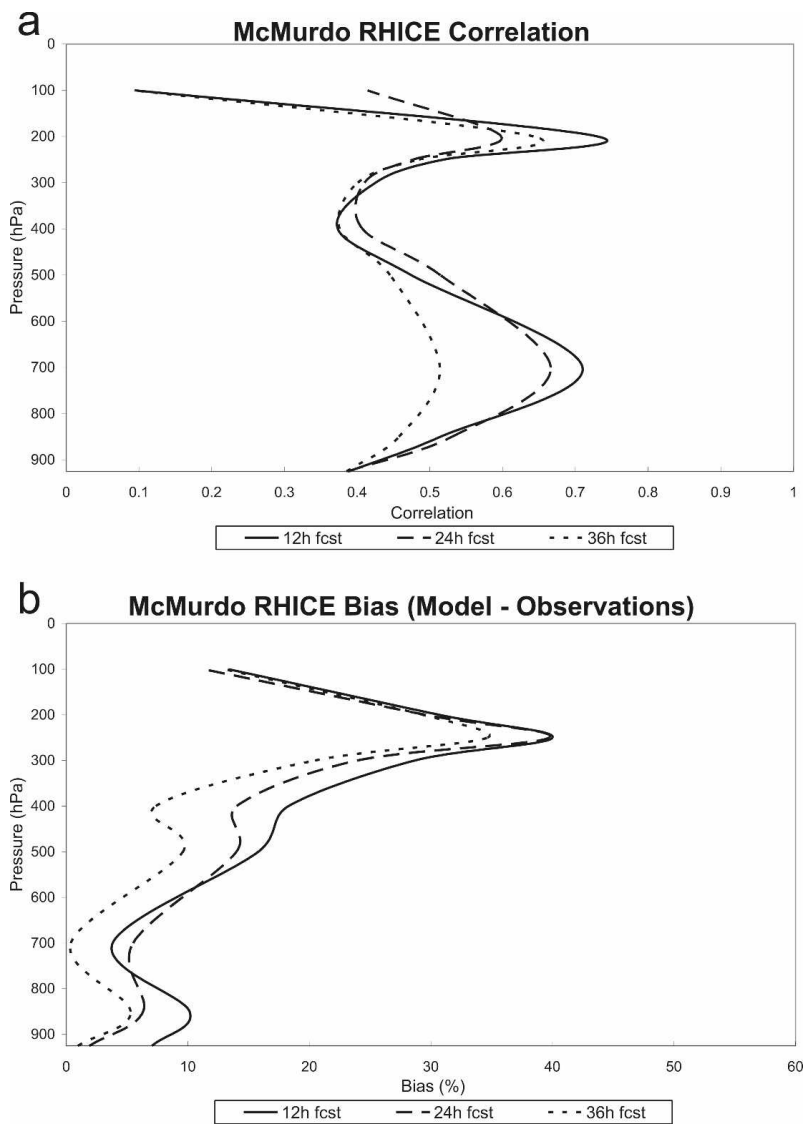

FIG. 2. Modeled relative humidity with respect to ice (a) correlations with observations and (b) biases (model - observations, \%) by forecast (fcst) hour (h), December 2003-February 2005.

correlation at 700 and at $200 \mathrm{hPa}$, with the magnitude decreasing markedly at the former with increasing forecast hour. Large changes at other levels with increasing forecast hour are not readily seen, despite the fact that the McMurdo radiosonde is assimilated into AMPS as part of the model initial conditions. Figure $2 b$ reveals an increasing positive bias with height that peaks at $\sim 40 \%$ at $250 \mathrm{hPa}$, near the annual average tropopause, suggesting that the model has difficulty resolving this boundary. There is an interesting reduction in the bias throughout forecast hour at all levels, the cause for which is not known. The relatively minimal biases at 400 and $100 \mathrm{hPa}$ demonstrate that both the model and the observations generally produce low values of relative humidity at these levels, except for a few outliers, which lead to the lower correlation seen at these levels (Fig. 2a). The positive (moist) biases between 400 and $100 \mathrm{hPa}$, greater than even the uncorrected measurement errors for the RS92 radiosondes, are a result of an insufficient decrease in moisture with height in the model, as the vertical moisture gradient in AMPS is much weaker than observed up to $200 \mathrm{hPa}$.
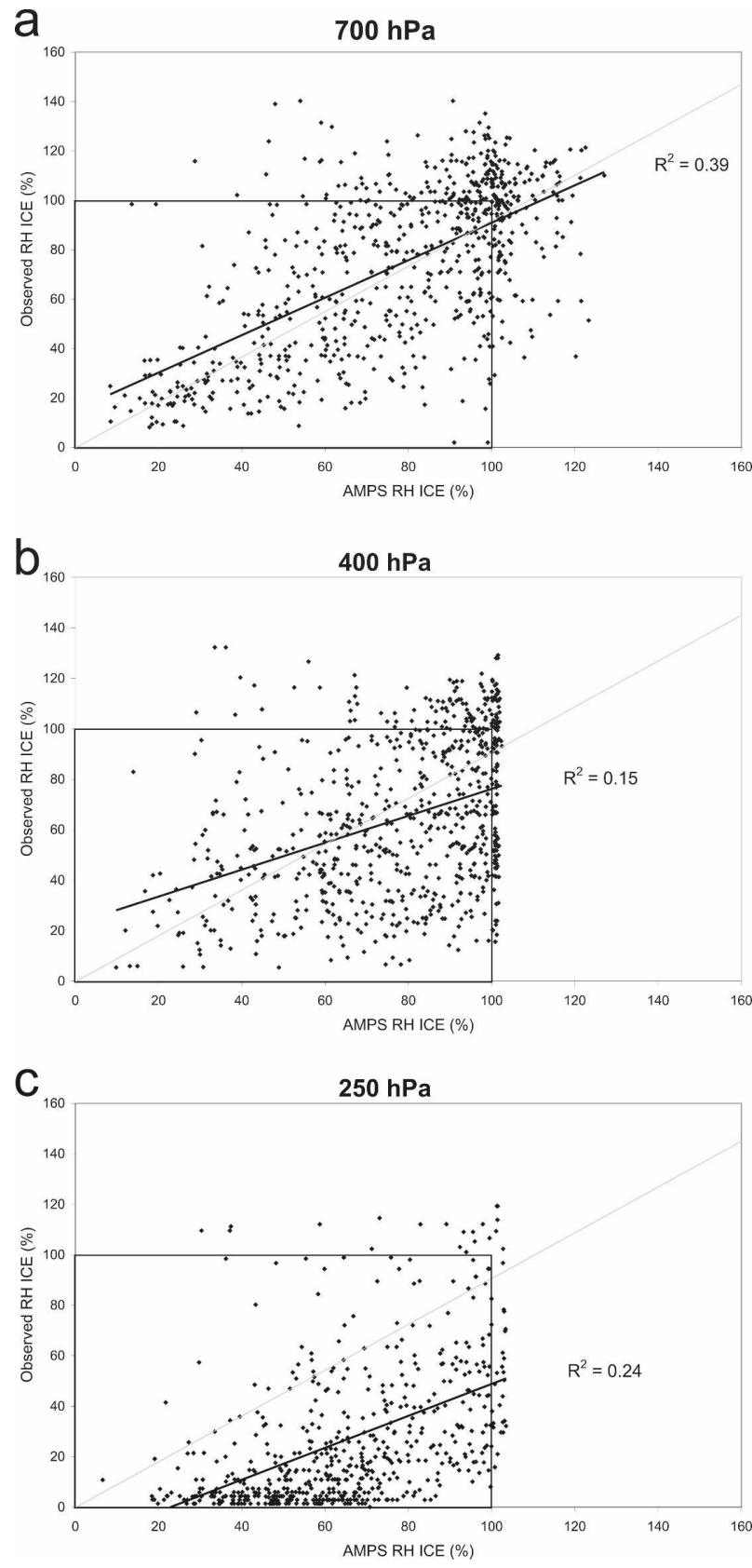

FIG. 3. Scatterplots of modeled relative humidity with respect to ice ( $x$ axis) vs observed relative humidity with respect to ice ( $y$ axis) for (a) 700, (b) 400, and (c) $250 \mathrm{hPa}$. Regression lines for each scatter and the $r^{2}$ values are plotted in each figure. The gray line represents one-to-one correspondence $(x=y)$, and the boxed region is drawn for $100 \%$ relative humidity with respect to ice to indicate saturation occurrence.

Examining scatterplots of modeled versus observed $\mathrm{rh}_{\text {ice }}$ for select pressure levels (700 hPa in Fig. 3a, 400 $\mathrm{hPa}$ in Fig. 3b, and $250 \mathrm{hPa}$ in Fig. 3c) provides additional information regarding the moisture prediction skill. Here, all forecast hours are retained for compari- 
son; thus, during the summer, two forecasts are compared to the 1200 UTC data (the 12- and 36-h forecasts). All months are also retained as the seasonal changes in relative humidity correlation and bias are relatively small (not shown), in agreement with Bromwich et al. (2005) who similarly find little interseasonal variation in model skill for many of the state variables (i.e., temperature, pressure). The scatterplots in Fig. 3 also have a one-to-one line that helps to display biases, as positive (negative) biases fall below (above) this line. A regression line and the $r^{2}$ value are also plotted for each figure to examine the correlation and persistent biases, while values outside of the rectangles in Fig. 3 indicate saturation with respect to ice (hereafter sat ${ }_{i c e}$ ), an important characteristic for cloud formation.

As expected from Fig. 2, the scatterplots demonstrate the best overall skill at $700 \mathrm{hPa}$ (Fig. 3a), where the regression line is very similar to the one-to-one line and the $r^{2}$ value is the highest. At $700 \mathrm{hPa}$, sat ice $_{\text {is }}$ also predicted well, and at comparable frequencies in both the model and observations. The $r^{2}$ value is lowest at $400 \mathrm{hPa}$ (Fig. 3b), clearly generated by the large spread of the observed $\mathrm{rh}_{\text {ice }}$ values at all modeled $\mathrm{rh}_{\text {ice }}$ values. In contrast to this, the observed $\mathrm{rh}_{\text {ice }}$ values are often very small while the model has a much greater range in $\mathrm{rh}_{\text {ice }}$ values at $250 \mathrm{hPa}$ (Fig. 3c). However, at 400 and $250 \mathrm{hPa}$, AMPS predicts $\mathrm{rh}_{\text {ice }}>100 \%$ much more frequently than observed, and for a much greater range of observed $\mathrm{rh}_{\text {ice }}$ values.

\section{b. Cloud fraction}

In AMPS, CF is calculated from AMPS model output, based on the integrated cloud optical depth, $\tau$, adapted from the Community Climate Model, version 2 (CCM2), radiation scheme that is employed by PMM5 (Hack et al. 1993):

$$
\mathrm{CF}=\tau=\sum_{\mathrm{sfc}}^{\text {toa }}(0.1 \mathrm{CLWP}+0.0735 \mathrm{CIWP}),
$$

where CLWP is the cloud liquid water path and CIWP is the cloud ice water path at each $1 / 2$ sigma level, and sfc indicates the surface and toa indicates the top of the atmosphere (50 hPa in AMPS). The CLWP and CIWP are in grams per square meter, and are based on the microphysical quantities of cloud liquid water and ice concentrations (CLW and CICE, respectively; $\mathrm{g} \mathrm{kg}^{-1}$ ), as given in Eqs. (2) and (3):

$$
\begin{aligned}
& \mathrm{CLWP}=\left[\frac{p}{(T \times 287)}\right] \times \mathrm{CLW} \times d z \text { and } \\
& \mathrm{CIWP}=\left[\frac{p}{(T \times 287)}\right] \times \mathrm{CICE} \times d z,
\end{aligned}
$$
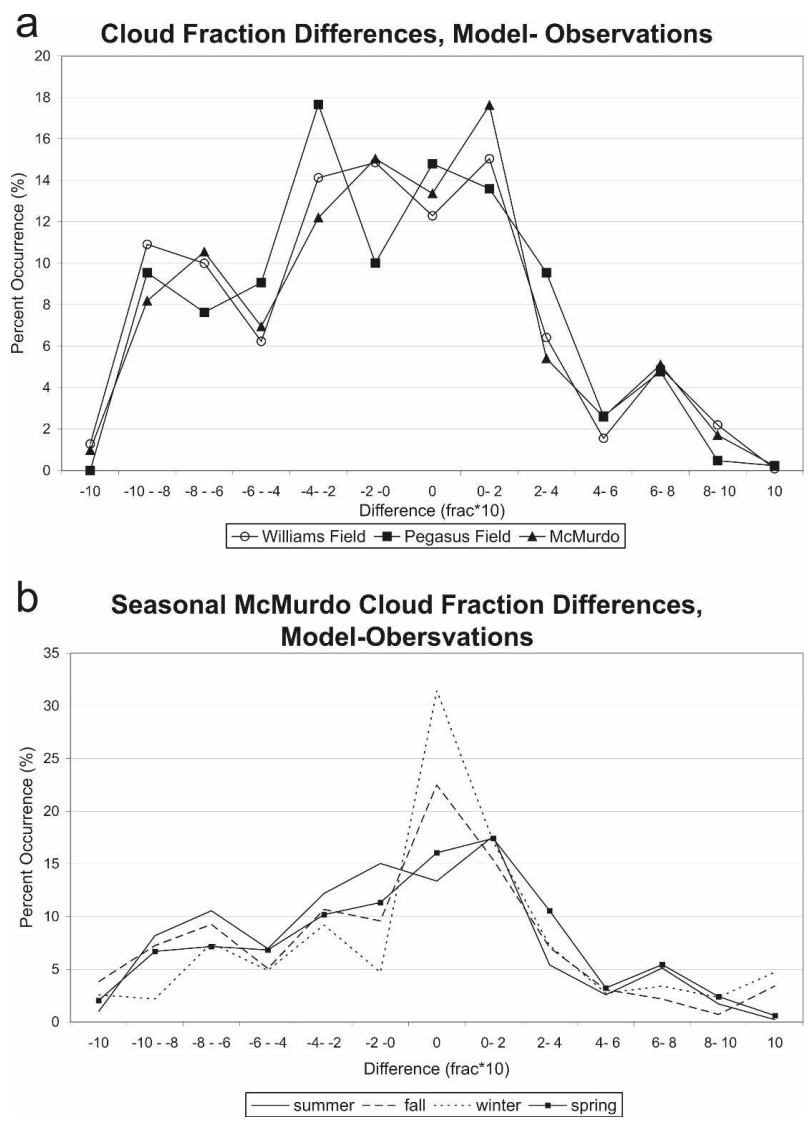

FIG. 4. Cloud fraction difference (model - observations) distributions for (a) Williams Field, Pegasus Field, and McMurdo for summer and (b) McMurdo only, but by season.

where $p$ is the pressure $(\mathrm{Pa})$ and $T$ is the temperature (K) at each $1 / 2$ sigma level, and $d z$ is the change in height $(\mathrm{m})$ between the $1 / 2$ and full sigma levels, which accounts for forecast pressure changes. Cassano et al. (2001) provide further details regarding how the CLWP and CIWP are determined in PMM5. The constants $0.1 \mathrm{~m}^{2} \mathrm{~g}^{-1}$ and $0.0735 \mathrm{~m}^{2} \mathrm{~g}^{-1}$ in Eq. (1) are longwave absorption coefficients, but were derived for midlatitude conditions as part of the CCM2 radiation scheme. The CF is restricted to be less than or equal to 1 .

Values for the CF extracted for the model grid points representing each of the locations in Fig. 1 are compared with observations to better understand the cloud variability within AMPS. The CF error distribution (model - observations) is displayed in Fig. 4a for the summer seasons when measurements are routinely taken at all three locations, and Fig. $4 \mathrm{~b}$ for all seasons at McMurdo; Table 1 lists the statistical characteristics of the distributions presented in Fig. 4. Notably, the performance at all three stations in summer is very similar, despite the fact that McMurdo is protected from the frequent southerly winds over the Ross Ice Shelf that 
TABLE 1. Statistical characteristics of the cloud fraction error distributions in Figs. 4 and 5, and for South Pole station: number of forecasts verified (No. of obs); average observed cloud fraction (mean obs CF); average difference (model - observations) (bias); and the two-tailed statistical probability that the mean modeled CF is the same in the new and old CF algorithms ( $p$ level).

\begin{tabular}{|c|c|c|c|c|c|c|c|c|}
\hline \multirow[b]{2}{*}{ Location } & \multirow[b]{2}{*}{ Season } & \multirow{2}{*}{$\begin{array}{c}\text { No. of } \\
\text { obs }\end{array}$} & \multirow{2}{*}{$\begin{array}{c}\text { Mean } \\
\text { obs CF }\end{array}$} & \multicolumn{2}{|c|}{ Old CF algorithm } & \multicolumn{2}{|c|}{ New CF algorithm } & \multirow[b]{2}{*}{$p$ level } \\
\hline & & & & Bias & Correlation & Bias & Correlation & \\
\hline McMurdo & Summer & 1688 & 0.620 & -0.137 & 0.394 & -0.050 & 0.394 & 0.000 \\
\hline Williams Field & Summer & 1090 & 0.632 & -0.201 & 0.345 & -0.113 & 0.342 & 0.000 \\
\hline Pegasus South & Summer & 419 & 0.698 & -0.136 & 0.364 & -0.021 & 0.369 & 0.000 \\
\hline McMurdo & Fall & 505 & 0.576 & -0.087 & 0.459 & 0.009 & 0.453 & 0.001 \\
\hline McMurdo & Winter & 445 & 0.358 & 0.028 & 0.419 & 0.105 & 0.389 & 0.013 \\
\hline McMurdo & Spring & 802 & 0.638 & -0.038 & 0.428 & 0.050 & 0.457 & 0.000 \\
\hline South Pole station & Summer & 1652 & 0.569 & -0.250 & 0.427 & -0.129 & 0.455 & 0.000 \\
\hline South Pole station & Fall & 851 & 0.449 & 0.048 & 0.506 & 0.178 & 0.428 & 0.000 \\
\hline South Pole station & Winter & 663 & 0.416 & -0.092 & 0.481 & 0.071 & 0.468 & 0.000 \\
\hline South Pole station & Spring & 765 & 0.595 & -0.128 & 0.566 & -0.002 & 0.534 & 0.000 \\
\hline
\end{tabular}

often bring cloud and snow to Pegasus and Williams Fields (cf. Fig. 10 of Bromwich et al. 2005). However, Fig. 4a and Table 1 shows that the model often underpredicts cloudiness throughout the year (largest during the warmer months) as determined by the $\mathrm{CF}$, in agreement with previous studies (Guo et al. 2003; Bromwich et al. 2005). However, this study disagrees with Guo et al. (2003), who relate this negative CF bias to a lowlevel dry bias, since our relative humidity comparisons indicate that AMPS has excessive $\mathrm{rh}_{\text {ice }}$ throughout the troposphere (Fig. 2b), albeit small positive biases closer to the surface. The correlation with the observations is slightly lower than the relative humidity correlations (cf. Table 1 and Fig. 2), but is in agreement with Bromwich et al. (2005).

To improve the relationship between observed and modeled $\mathrm{CF}$, several combinations of the coefficients for CLWP and CIWP in Eq. (1) (which were developed for midlatitude conditions) were tested to produce the distribution that best aligns with the observations and removes the negative bias (underprediction of clouds). In this process it was found that the coefficients 0.075 $\mathrm{m}^{2} \mathrm{~g}^{-1}$ for the CLWP and $0.170 \mathrm{~m}^{2} \mathrm{~g}^{-1}$ for the CIWP are the most optimal, where more than twice as much weight was given to the CIWP. Lubin (1994) finds that the emissivity of maritime Antarctic clouds is smaller than the CLWP used in the NCAR Community Climate Model 1, and therefore finds that a better absorption coefficient for CLWP was $0.065 \mathrm{~m}^{2} \mathrm{~g}^{-1}$, very similar to the $0.075 \mathrm{~m}^{2} \mathrm{~g}^{-1}$ CLWP determined here.

Notably, Lachlan-Cope et al. (2001) find more ice crystals present in clouds over the Avery Plateau on the Antarctic Peninsula than expected in the midlatitudes, confirming that more weight needs to be given to the CIWP for Antarctic clouds. Their study also found supercooled liquid water in the clouds they observed, while tethered cameras flown into clouds at the South
Pole station, representative of the interior of the continent, have also noted the presence of supercooled liquid water primarily during December and January and rarely during October-November and FebruaryMarch (M. Town 2006, personal communication). Together, these limited studies suggest ice particles dominate Antarctic cloudiness but that supercooled liquid water is indeed present, especially during the warmer summer months; thus, at least some weight must be given to the CLWP in the CF algorithm.

Despite the fact that little is known on cloud variability in Antarctica, applying more weight to the CIWP substantially increases the ability for AMPS to accurately predict the CF amount, as indicated in Fig. 5 and the right columns of Table 1 . The modified algorithm produces a near-zero bias in all seasons except winter (which a Student's $t$ test indicates is statistically different from the previous distribution at $p<0.01$ ), and reduces the underprediction of clouds by as much as $5 \%$ on average at all sites. The modified CF algorithm also produces a better alignment with high values of relative humidity within the model and the overcast cloud layers (not shown), with improvements from the original to the modified algorithm leading to changes of as much as $20 \%$. However, given that the CF correlation does not change using the new algorithm suggests that AMPS is accurately predicting CICE variability, but not producing enough CLW variability to match with the observed CF (and therefore produce a higher correlation). This conjecture will be examined in section 5 .

\section{AMPS validation at South Pole station}

As the performance at McMurdo extends to other coastal stations (Bromwich et al. 2005), we now exam- 


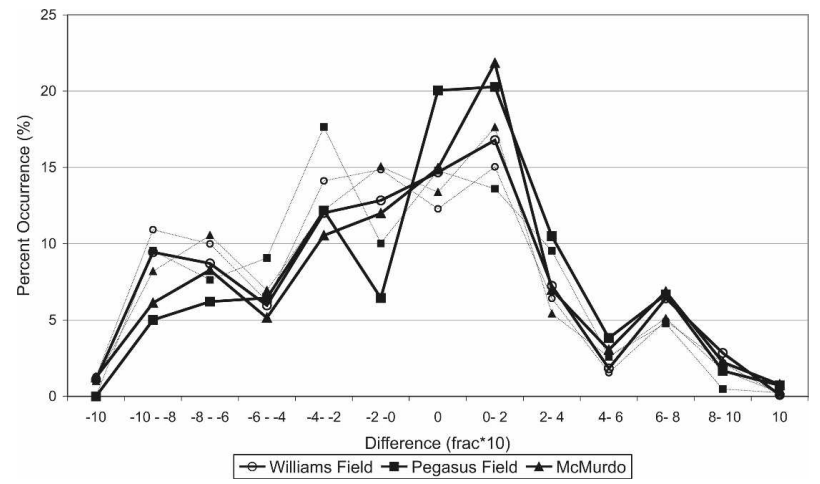

FIG. 5. As in Fig. 4a but for the modified CF algorithm (solid). The dashed lines are the values from the original CF algorithm (Fig. 4a).

ine the performance over the interior of the continent by employing observations from the South Pole station compared with AMPS data from the $30-\mathrm{km}$ grid, the only domain covering the region available in the AMPS archive. South Pole station was chosen as it was the only interior station to have radiosonde launches continuously throughout the year, which allows for examination of the relative humidity performance and cloud cover as was conducted for McMurdo.

\section{a. Relative humidity}

The relative humidity evaluations at South Pole station are presented in Fig. 6. Here, the AMPS $\mathrm{rh}_{\text {ice }}$ correlation with observations (Fig. 6a) ranges between 0.3 and 0.5 throughout much of the troposphere, slightly lower than that at McMurdo (Fig. 2a). The better performance above $250 \mathrm{hPa}$ is due to the reduced moisture variability in the upper troposphere-lower stratosphere over the continental interior, which is adequately depicted in AMPS despite the fact that the correlation drops notably at these levels with increasing forecast hour. Below $250 \mathrm{hPa}$, the 24-, 48-, and 72-h forecasts show similar (and higher) skill as only these forecasts align with the 0000 UTC soundings taken during the off season. The lower skill at the other forecast hours is most likely tied to increased moisture variability in the lower troposphere during the summer at South Pole station, which is not captured as well in AMPS. The biases (Fig. 6b) are $\sim 10 \%$ larger than at McMurdo (Fig. 2b), and also increase with height to $\sim 50 \%$ at 250 $\mathrm{hPa}$, which is also near the tropopause. As at McMurdo, this increasing bias with height is related to an inaccurate vertical depletion of moisture that also exists over the continental interior in AMPS. Interestingly, the biases again decrease with increasing forecast hour, for uncertain reasons.
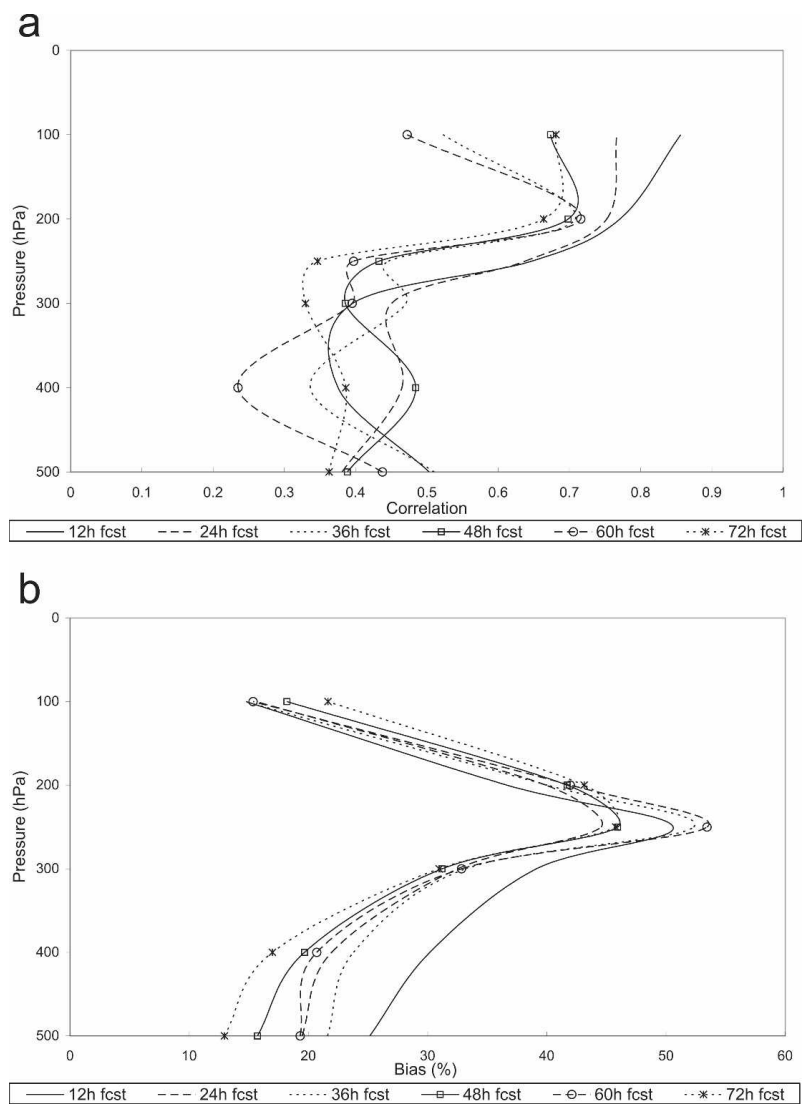

FIG. 6. As in Fig. 2 but for South Pole station.

\section{b. Cloud fraction}

Before CF comparisons can be made, some comments must first be made about the observed cloud cover at South Pole station, a much different environment than McMurdo. Many problems complicate the ground-based visual cloud cover observations at South Pole station, including the very thin nature of clouds at all levels through which the sun/stars are often seen [these conditions tend to favor partly cloud observations instead of overcast conditions; Mahesh et al. (2001); Bernhard et al. (2004); Town et al. (2007)], a 6-month period of complete darkness, making clouds difficult to observe, and extremely cold temperatures year round with especially strong inversion layers in the winter (Turner and Pendlebury 2007). Town et al. (2005) further note the persistent presence of "diamond dust" or clear-sky precipitation during the winter, which may also add to errors in observed cloud fraction. They note that the wintertime average cloud fraction obtained from spectral infrared data is $0.3-0.5$ greater than that obtained from visual observations. Therefore, the agreement between modeled and observed clouds should not align as well as at McMurdo, especially during the nondaylight hours. 
Seasonal CF statistics are presented for the original and the modified CF algorithms in the bottom rows of Table 1. Clouds are also underpredicted in AMPS using the original CF algorithm at South Pole station, and the mean bias is -0.135 for the time period considered. Notably, there is a much more marked seasonal cycle at South Pole station; the bias during austral fall is small and positive (0.048), while the bias is much farther from zero during the summer $(-0.250)$. However, the positive bias in fall may be related to a known negative bias in observed $\mathrm{CF}$ compared against independent data (Town et al. 2007). Incorporating the modified CF algorithm again substantially reduces the mean bias to -0.004 , effectively centering the error distribution over zero, with these changes being highly statistically significant $(p<0.001$; Table 1$)$. The exception is for fall, where a larger positive bias is introduced by switching from the original to the modified $\mathrm{CF}$ algorithm; the bias using the modified $\mathrm{CF}$ algorithm also becomes positive during winter, but both of these seasons are marked with a negative bias in observed cloud cover (Town et al. 2007), so AMPS is likely predicting reliable CF amounts in these seasons. During the other seasons, the biases improve by $\sim 0.12$ and are closer to zero than when using the previous CF values. This further demonstrates that adjustments to the coefficients in the empirical CF algorithm can reduce the bias not only in the McMurdo region, but over the entire Antarctic continent. However, the fact that the correlation again changes little with the new CF algorithm suggests changes in the model physics, and particularly in the calculation of CLW (given that the changes in the CF algorithm are primarily tied to large changes in the weight given to CICE), are needed to improve the prediction of $\mathrm{CF}$ temporal variability.

Finally, the cloud prediction performance at South Pole station is evaluated by forecast hour for various sky coverage criteria (overcast, $\mathrm{CF}>0.8$; partly cloudy, $0.2 \leq \mathrm{CF} \geq 0.8$; and clear, $\mathrm{CF}<0.2$ ). To facilitate interpretation, only the percentage of matched forecasts (both the model and the observation indicate the same sky coverage) with respect to the total number of observations is plotted against forecast hour (Fig. 7). The modified CF greatly improves the number of matched forecasts of the overcast conditions by as much as $20 \%$, with only slight decreases in the number of matches for clear and partly cloudy conditions for the early to midforecast hours. However, these changes are much smaller than the large improvements gained in the prediction of overcast conditions, which have the most impact on aircraft operations. Additionally, other tests (not shown) demonstrate that the model rarely predicts $\mathrm{CF}$ that falls in the partly cloudy range, but

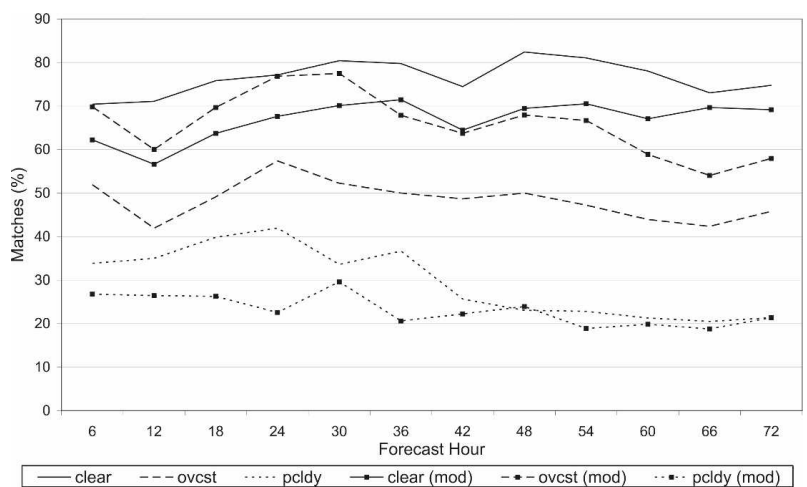

FIG. 7. Percent matches for South Pole station by forecast hour grouped by various sky conditions. Time series with markers indicate matches from the new cloud fraction algorithm.

rather tends to predict overcast and clear conditions instead, in agreement with the known $U$ distribution of observed cloud cover at South Pole station (Town et al. 2007). Thus, the forecast skill is the lowest for the partly cloudy sky coverage regardless of the empirical algorithm employed. In contrast to other fields, Fig. 7 shows that overall the model skill for cloud prediction does not vary substantially between forecast hours, although there appears to be some slight degradation in time for overcast and partly cloudy conditions, especially the latter using the original algorithm. A possible explanation for why fewer changes with forecast hour are seen in the cloud predictions (Fig. 7) compared to the relative humidity predictions (Figs. 2 and 6 ) is that relative humidity observations are assimilated into the initial conditions in AMPS, while clouds are generated by the model physics. Bromwich et al. (1999) note that the distinction between coastal and interior moisture conditions lessens with forecast time in older versions of the National Centers for Environmental Prediction (NCEP) operational Global Spectral Model. Notably, NCEP's Aviation Model (AVN) supplies the initial and boundary conditions for AMPS, so the problems observed in Bromwich et al. (1999) may still affect the current AMPS forecasts.

\section{The pseudosatellite product}

The previous validation tests have reached an important conclusion regarding the cloud variability in AMPS: changes to the coefficients of CLWP and CIWP in Eq. (1) produce a CF that has near-zero bias with observations, while the microphysics scheme appears to not produce enough CLW, leading to the low CF correlation. Although AMPS has a strong positive moisture bias near the tropopause, the model relative humidity values infrequently achieve saturation with re- 


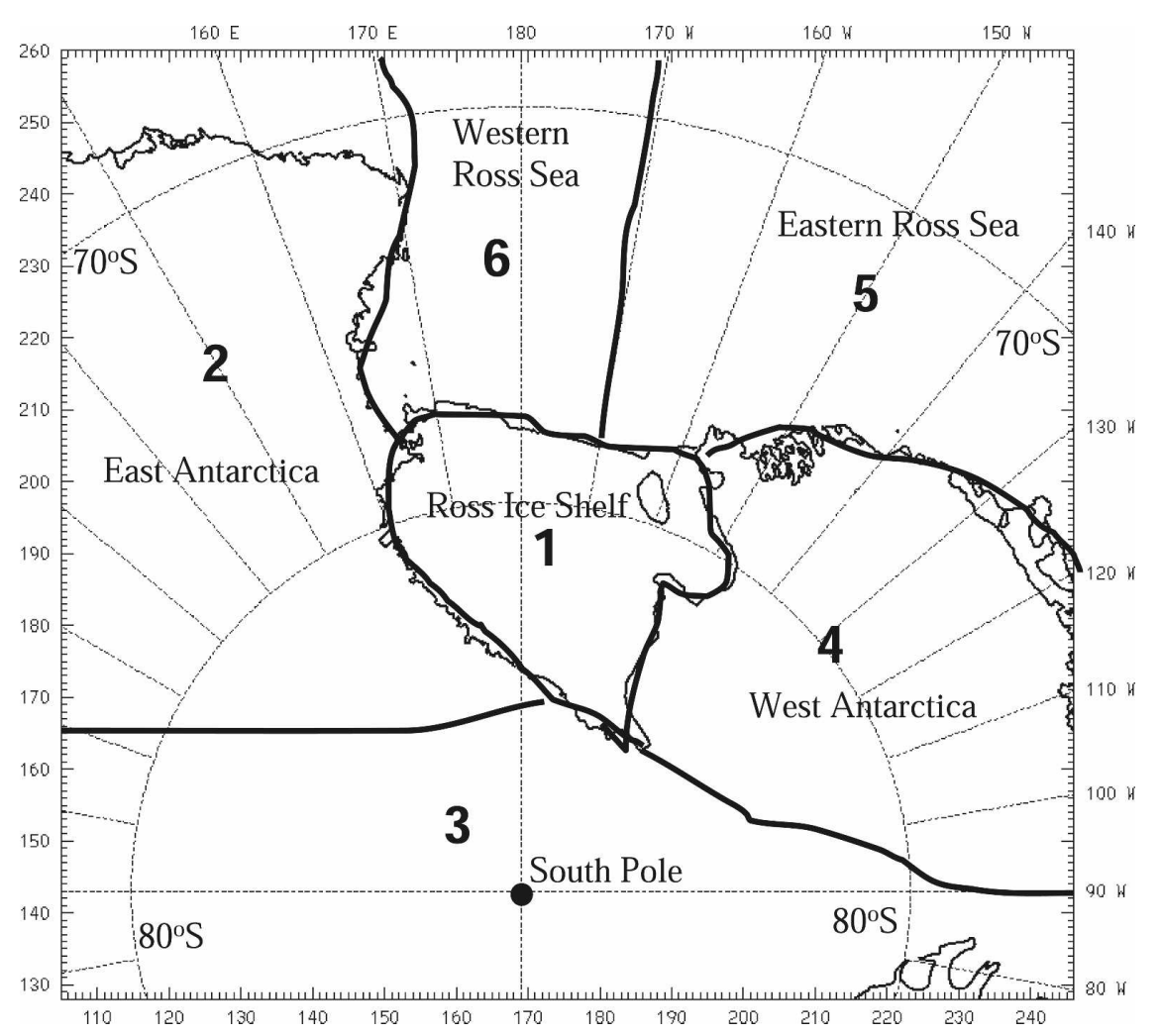

FIG. 8. Locations of the regions used in performing the quantitative validation of the pseudosatellite product: 1, Ross Ice Shelf; 2, East Antarctica; 3, South Pole region; 4, West Antarctica; 5, eastern Ross Sea; and 6, western Ross Sea.

spect to ice (cf. Fig. 3c), which suggests that the positive moisture biases are not influencing the $\mathrm{CF}$ bias. Further, Antarctic clouds rarely form as high as the tropopause (e.g., Mahesh et al. 2001), and high cloud conditions are classified starting at $11000 \mathrm{ft}(\sim 600 \mathrm{hPa})$ above mean sea level (Turner and Pendlebury 2007). To assess the model performance further, it is necessary to examine a more complete visualization of the cloud characteristics, such as in satellite imagery, as CF only details cloud coverage at a single point and not the spatial variability of cloud height, thickness, or layers. Visualizations that display all these cloud features would also be very beneficial operationally, as Antarctic forecasters rely heavily on available satellite imagery (cloud characteristics) to track the timing and coverage of cloud layers and their associated precipitation (if any) due to the lack of observations of these fields.

To aid in this regard, the Polar Meteorology Group of the Byrd Polar Research Center recently developed and initially tested a "pseudosatellite" product. This product, now available in real time as a standard forecast product from AMPS (see online at http://box. $\mathrm{mmm}$.ucar.edu/rt/mm5/amps/), uses the vertically integrated CLW and CICE species from AMPS [see Eqs.
(2) and (3)] to generate a pseudosatellite image that roughly follows the Antarctic infrared color composites generated by the AMRC. [Vukicevic et al. (2004) describe a similar product based on cloud mixing ratio.] The product improves upon the $\mathrm{CF}$ and cloud-base products in AMPS as it separates low clouds, displayed with blue to gray shades in the product, specified from the vertical integral of the CLW species, from higher clouds (white shades) depicted from the vertical integral of the CICE. The pseudosatellite was first available in late 2005 , and was used by forecasters during the 2005-06 and 2006-07 field seasons as it successfully provided additional guidance on cloud movement and associated precipitation.

During January 2006, the first author visited McMurdo and conducted a real-time evaluation of the available 0000 UTC initialization time pseudosatellite products on the $20-\mathrm{km}$ resolution grid (see Fig. 8 for study area), since the continent-wide horizontal resolution increased from 30 to $20 \mathrm{~km}$ in late 2005 . This particular region was chosen as it is used the most frequently by forecasters and is archived on site, allowing easy access during the validation period. The evaluations were conducted using the $12-, 36-$, and 60 -h fore- 
TABLE 2 . The $2 \times 2$ contingency tables and associated statistical skill scores as described in Murphy (1996) and Wilks (2006) for the low cloud performance of the pseudosatellite product for the regions defined in Fig. 8. To be counted as a match (i.e., clouds-clouds or clear-clear), the CLW content in the pseudosatellite product must closely match the coverage in the concurrent satellite imagery. Using the schematic, the chi-squared probability is the statistical probability that $a, b, c$, and $d$ are independent; percent correct $=$ $(a+d) / n$, where $n$ is the total observations (35 here); threat score $=a /(a+b+c)$; bias $=(a+b) /(a+c)$; false alarm ratio $=$ $b /(a+b)$; false alarm $=b /(b+d)$; hit rate $=a /(a+c)$; HSS is the Heidke skill score; PSS is the Peirce skill score; CSS is the Clayton skill score; and GSS is the Gilbert skill score. HSS, PSS, and CSS all range from -1 to 1 , with 1 indicating perfect forecast skill, 0 indicating random forecast performance, and -1 indicating the worst possible skill; the GSS ranges from 0 to 1 , with 1 indicating perfect forecast skill.

\begin{tabular}{|c|c|c|c|c|c|c|c|c|c|c|c|c|c|c|}
\hline \multicolumn{3}{|c|}{ Schematic } & \multirow{3}{*}{\multicolumn{2}{|c|}{ Ross Ice Shelf }} & \multirow{3}{*}{\multicolumn{2}{|c|}{ East Antarctica }} & \multirow{3}{*}{\multicolumn{2}{|c|}{ South Pole region }} & \multirow{3}{*}{\multicolumn{2}{|c|}{ West Antarctica }} & \multirow{3}{*}{\multicolumn{2}{|c|}{ Eastern Ross Sea }} & \multirow{3}{*}{\multicolumn{2}{|c|}{ Western Ross Sea }} \\
\hline \multirow{3}{*}{$\frac{\text { AMPS }}{\text { Yes }}$} & \multicolumn{2}{|c|}{ Obs } & & & & & & & & & & & & \\
\hline & \multirow{2}{*}{$\frac{\text { Yes }}{a}$} & \multirow{2}{*}{$\begin{array}{c}\mathrm{No} \\
b\end{array}$} & & & & & & & & & & & & \\
\hline & & & 7 & 0 & 3 & 0 & 3 & 0 & 3 & 0 & 17 & 10 & 12 & 15 \\
\hline No & $c$ & $d$ & 22 & 6 & 8 & 24 & 12 & 20 & 26 & 6 & 8 & 0 & 3 & 5 \\
\hline $\begin{array}{l}\text { Chi-squ } \\
\text { proba }\end{array}$ & $\begin{array}{l}\text { ared } \\
\text { bility }\end{array}$ & & & & & & & & & & & & & \\
\hline Percent & correc & & & & & & & & & & & & & \\
\hline Threat s & core & & & & & & & & & & & & & \\
\hline Bias & & & & & & & & & & & & & & \\
\hline False al & arm ra & & & & & & & & & & & & & \\
\hline False al & $\operatorname{arm}$ & & & & & & & & & & & & & \\
\hline Hit rate & & & & & & & & & & & & & & \\
\hline HSS & & & & & & & & & & & & & & \\
\hline PSS & & & & & & & & & & & & & & \\
\hline CSS & & & & & & & & & & & & & & \\
\hline GSS & & & & & & & & & & & & & & \\
\hline
\end{tabular}

casts initialized from 12 to 24 January 2006 for a total of 35 forecasts (missing the 60-h forecast from 24 January). Only these forecast hours were used since they represent the most spatially complete concurrent Defense Meteorological Satellite Program (DMSP) thermal infrared satellite image $(\sim 0.5 \mathrm{~km}$ resolution), with which the pseudosatellite forecasts were compared to determine the skill in the cloud placement (coverage and location) and movement (timing and temporal changes in coverage). The validations were also made by regions (Fig. 8) that together cover many more different synoptic environments than were previously evaluated at South Pole station and McMurdo. Observed cloud heights in the imagery are determined by their contrast to the surface, and because middle clouds are not easily identified in these satellite images or in the pseudosatellite product, a comparison of this cloud type is not conducted explicitly here. However, it is possible that human error may lead to the incorrect categorization of any cloud level, and not just the midlevel clouds. Although the validation period is relatively short, it contains a diversity of weather features, suggesting that additional comparisons will yield similar results. We constructed $2 \times 2$ contingency tables, along with their associated verification statistics [see Murphy (1996) and Wilks (2006) for a detailed description of these statistics], for each region in Fig. 8 as a means of quantitatively evaluating the pseudosatellite product, separated by low clouds (Table 2) and high clouds (Table 3). Matched (clouds-clouds or clear-clear) forecasts were recorded when both the model and satellite imagery displayed nearly the same cloud cover in the same location for each region.

For low clouds (Table 2), the percent correct is often less than $50 \%$ for all regions, except for East Antarctica where AMPS accurately predicts the infrequent lowlevel cloudiness. Over the continent, the biases are all less than 0.3 , suggesting a strong underprediction of low clouds, while there is an overprediction of clouds in the western Ross Sea. The various skill scores, with the exception of the eastern Ross Sea, are weakly positive, suggesting a slight skill above random forecasts, while the negative skill scores in the eastern Ross Sea imply that the model prediction of low cloudiness in this region is less than would be obtained by chance, governed by the 1.0 false alarm ratio (i.e., the inability to accurately predict clear conditions in the region). This assessment of the low clouds is in direct agreement with the conjecture that the model has difficulty in predicting the CLW variability, which leads to low a CF correlation with the observations.

Turning to the high cloud verification (Table 3), a greater level of skill is attained with the percent correct being above $80 \%$ in the majority of the regions, biases 
TABle 3. As in Table 2, but for high clouds and CICE.

\begin{tabular}{|c|c|c|c|c|c|c|c|c|c|c|c|c|c|c|}
\hline \multicolumn{3}{|c|}{ Schematic } & & & & & & & & & & & & \\
\hline \multirow{3}{*}{$\frac{\text { AMPS }}{\text { Yes }}$} & \multicolumn{2}{|c|}{ Obs } & & & & & & & & & & & & \\
\hline & \multirow{2}{*}{$\frac{\text { Yes }}{a}$} & \multirow{2}{*}{$\frac{\text { No }}{b}$} & \multicolumn{2}{|c|}{ Ross Ice Shelf } & \multicolumn{2}{|c|}{ East Antarctica } & \multicolumn{2}{|c|}{ South Pole region } & \multicolumn{2}{|c|}{ West Antarctica } & \multicolumn{2}{|c|}{ Eastern Ross Sea } & \multicolumn{2}{|c|}{ Western Ross Sea } \\
\hline & & & 9 & 0 & 23 & 1 & 18 & 0 & 19 & 0 & 11 & 4 & 12 & 6 \\
\hline No & $c$ & $d$ & 18 & 8 & 3 & 8 & 5 & 12 & 7 & 9 & 2 & 18 & 5 & 12 \\
\hline \multicolumn{3}{|c|}{$\begin{array}{c}\text { Chi-squared } \\
\text { probability }\end{array}$} & \multicolumn{2}{|c|}{0.06} & \multicolumn{2}{|c|}{$<0.001$} & \multicolumn{2}{|c|}{$<0.001$} & \multicolumn{2}{|c|}{$<0.001$} & \multicolumn{2}{|c|}{$<0.001$} & \multicolumn{2}{|c|}{0.73} \\
\hline \multicolumn{3}{|c|}{ Percent correct } & \multicolumn{2}{|c|}{48.57} & \multicolumn{2}{|c|}{88.57} & \multicolumn{2}{|c|}{85.71} & \multicolumn{2}{|c|}{80.00} & \multicolumn{2}{|c|}{82.86} & \multicolumn{2}{|c|}{68.57} \\
\hline \multicolumn{3}{|c|}{ Threat score } & \multicolumn{2}{|c|}{0.33} & \multicolumn{2}{|c|}{0.85} & \multicolumn{2}{|c|}{0.78} & \multicolumn{2}{|c|}{0.73} & \multicolumn{2}{|c|}{0.65} & \multicolumn{2}{|c|}{0.52} \\
\hline \multicolumn{3}{|c|}{ Bias } & \multicolumn{2}{|c|}{0.33} & & & & & & & & & & \\
\hline False al & arm ra & tio & & & & & & & & & & & & \\
\hline False al & arm & & & & & & & & & & & & & \\
\hline Hit rate & & & & & & & & & & & & & & \\
\hline HSS & & & & & & & & & & & & & & \\
\hline PSS & & & & & & & & & & & & & & \\
\hline CSS & & & & & & & & & & & & & & \\
\hline GSS & & & & & & & & & & & & & & \\
\hline
\end{tabular}

close to 1 (i.e., no bias), and skill scores above 0.7 in most cases. The high cloud performance is the weakest in the Ross Ice Shelf and western Ross Sea regions; however, in comparison with the low cloud predictions, AMPS does a remarkable job with the high cloud variability. These findings further support the claim that the low CF correlation is dominated by the inadequate variability of CLW in AMPS, but that CF amount is dominated by the CICE content, making AMPS reliable to use for studies based on CF amount or ice-only (high) cloud variability.

Individual comparisons are demonstrated in Figs. 9 and 10. First, Fig. 9 displays many of the strengths in the current pseudosatellite product, based on the 42-h forecast pseudosatellite product from the 0000 UTC 17 January 2006 initialization along with a corresponding Moderate Resolution Imaging Spectroradiometer (MODIS) thermal infrared satellite image at 3-km resolution. Note that although DMSP imagery was employed in the validation, the MODIS images are displayed in Figs. 9 and 10 as they are of better quality than the concurrent DMSP images; the final conclusions are not dependent on satellite type. In Fig. 9, a short-wave trough, depicted as an arc-shaped band of high clouds, is well captured by the pseudosatellite product (1 in Fig. 9). A line of high clouds stretching onto the East Antarctic coast is also well represented by the pseudosatellite product ( 2 in Fig. 9), and low clouds in the western Ross Sea are depicted with modest skill ( 3 in Fig. 9). The movement of these features is also in good agreement with the satellite imagery. However, the low clouds over the Ross Ice Shelf and East Antarctica (4 and 5, respectively, in Fig. 9) are not de- picted in the pseudosatellite product, which reflects the quantitative evaluation given in Table 2.

Figure 10 presents the validation from the 1200 UTC 21 January 2006 initialization. Here, the high clouds across the northern extent of the domain (1 in Fig. 10) and those in West Antarctica including the South Pole region (2 in Fig. 10) are fairly well captured during this forecast cycle. Based on the cloud structure, the model also depicts a low-level circulation in the Ross Sea (3 in Fig. 10), although with much more cloudiness than observed. Despite these resemblances, many features in the satellite image do not appear in the pseudosatellite product in Fig. 10, specifically, the extent of the lowand midlevel cloudiness over the Ross Ice Shelf (4 in Fig. 10) and high clouds over the Transantarctic Mountains (5 in Fig. 10). The validations from Table 2 similarly demonstrate deficient cloud liquid water (i.e., low cloud prediction) over the Ross Ice Shelf, as well as the lowest skill of any of the regions in predicting high cloud cover in Table 3 .

Tables 2 and 3 and Figs. 9 and 10 demonstrate that the pseudosatellite product does a reasonable job of predicting the high clouds, but does not predict the low-level clouds with much skill. This leads to an interesting dichotomy where diagnostic values of $\mathrm{CF}$ at both McMurdo and South Pole station using the modified empirical CF algorithm align well with ground-based visual observations, despite the fact that the model does not produce enough low clouds (or conversely, cloud liquid water) across the continent. There are at least two reasons that might explain this disparity. First, the diagnostic CF [Eq. (1)] depends strongly on the modeled CIWP, especially in the modified algorithm, and 

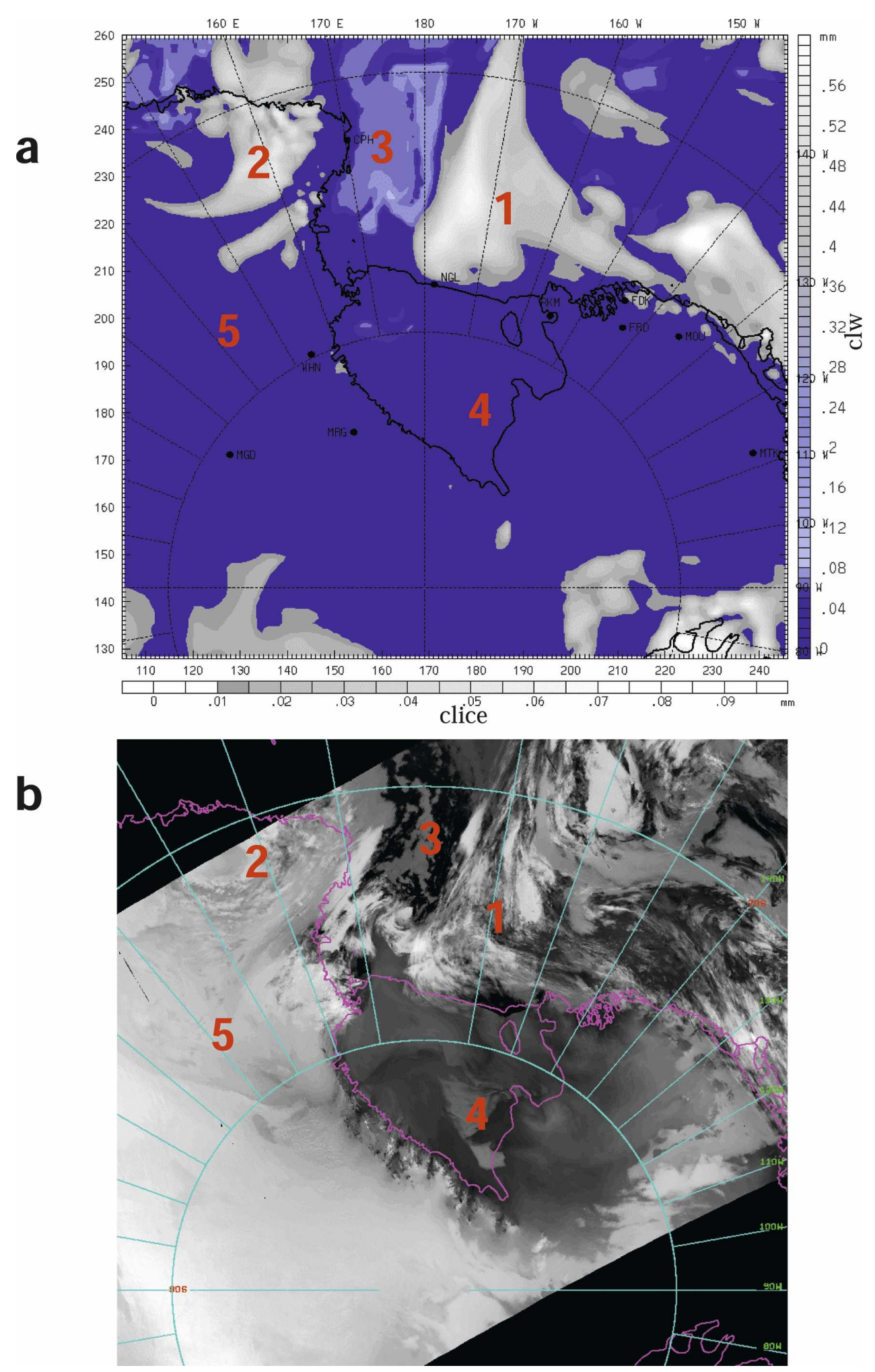

FIG. 9. (a) AMPS 0000 UTC 17 Jan 42-h pseudosatellite forecast (valid at 1800 UTC 18 Jan) and (b) MODIS infrared composite satellite image valid between 1815 and 1830 UTC 18 Jan. The numbers refer to clouds depicted by the model and their representation in the satellite imagery. The $x$ and $y$ axis labels in (a) correspond to the gridpoint locations on the 20-km grid (small map in Fig. 1). Black portions in the satellite image have no image data. See text for details. 

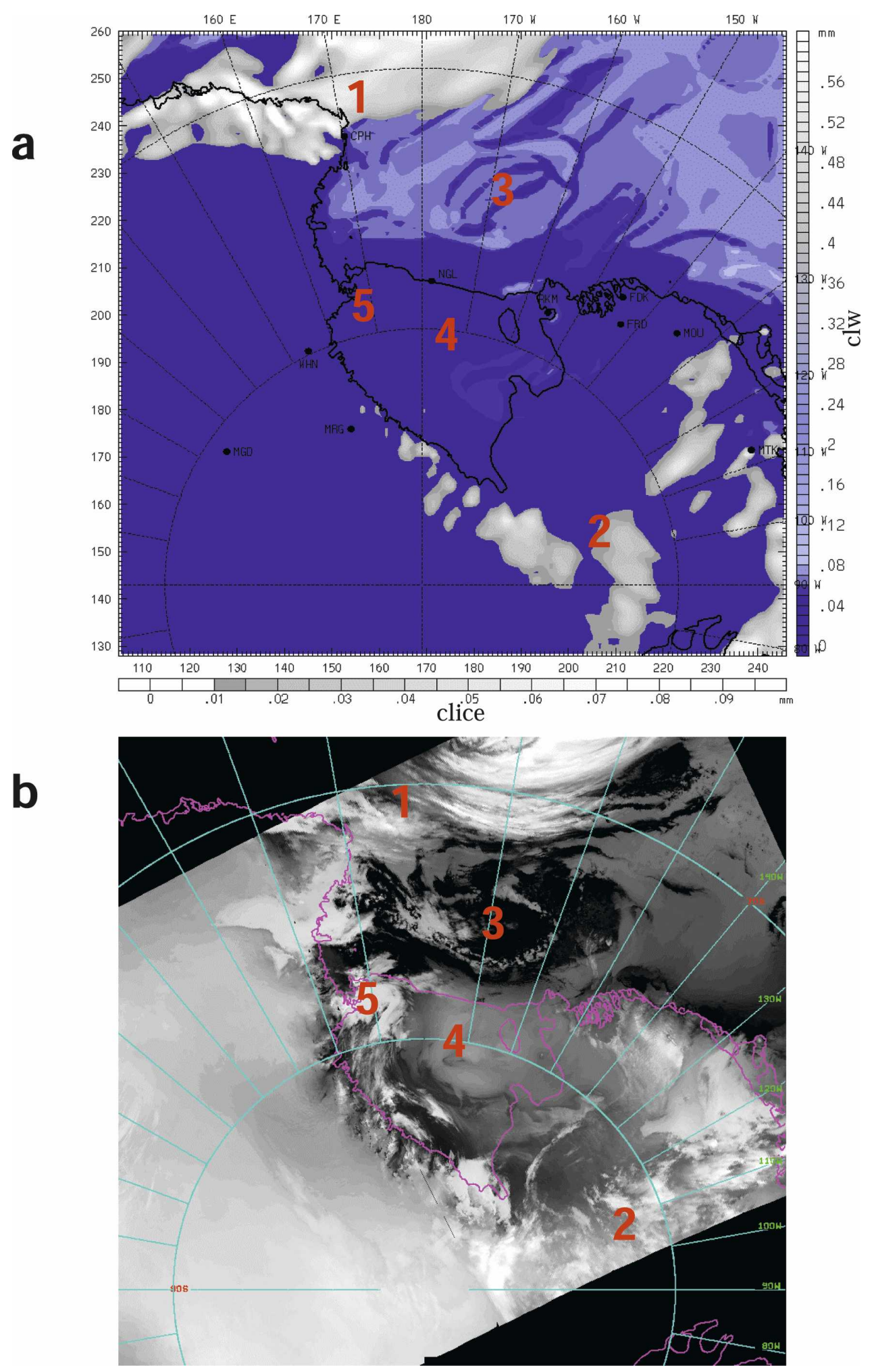

FIG. 10. (a) AMPS 12 UTC 21 Jan 45-h pseudosatellite forecast (valid at 0900 UTC 23 Jan) and (b) MODIS infrared satellite composite image valid between 0915 and 0920 UTC 23 Jan. The numbers refer to clouds depicted by the model and their representation in the satellite imagery. The $x$ and $y$ axis labels in (a) correspond to the gridpoint locations on the 20-km grid (small map in Fig. 1). Black portions in the satellite image have no image data. See text for details. 
a

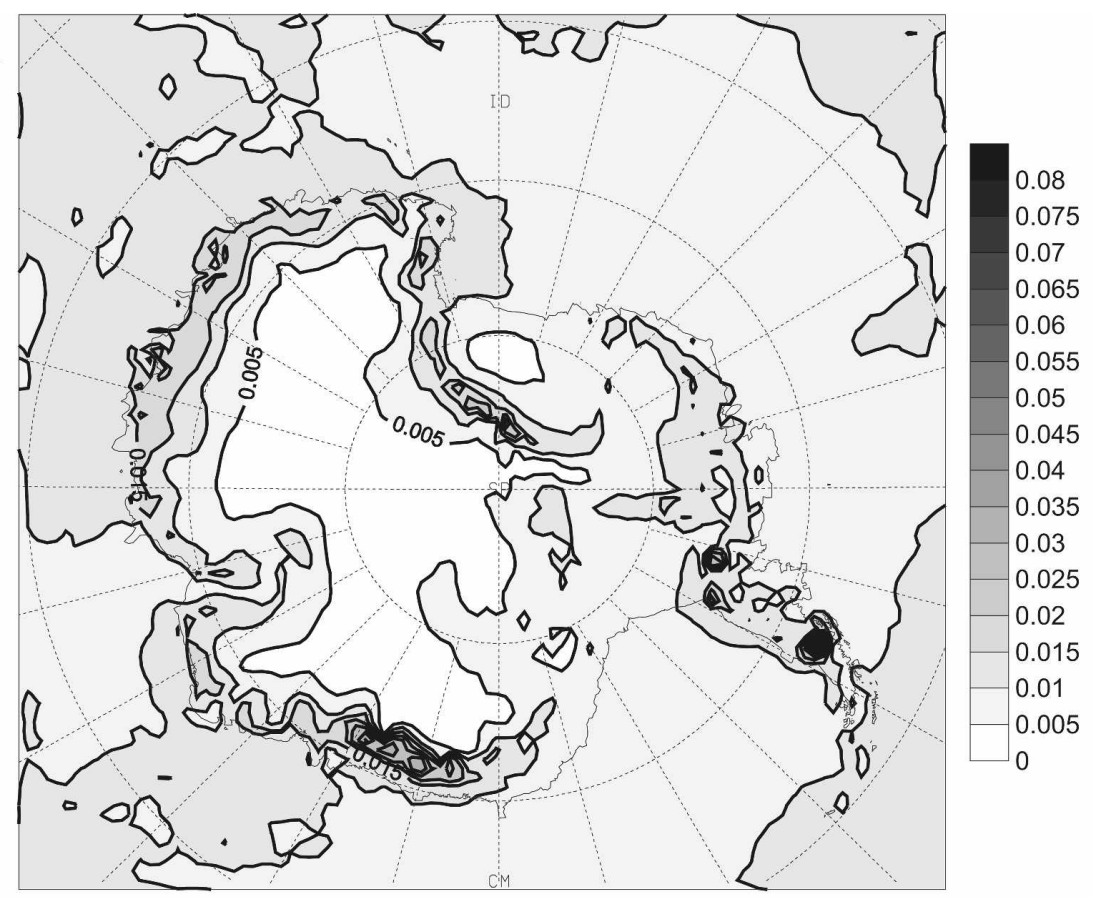

b

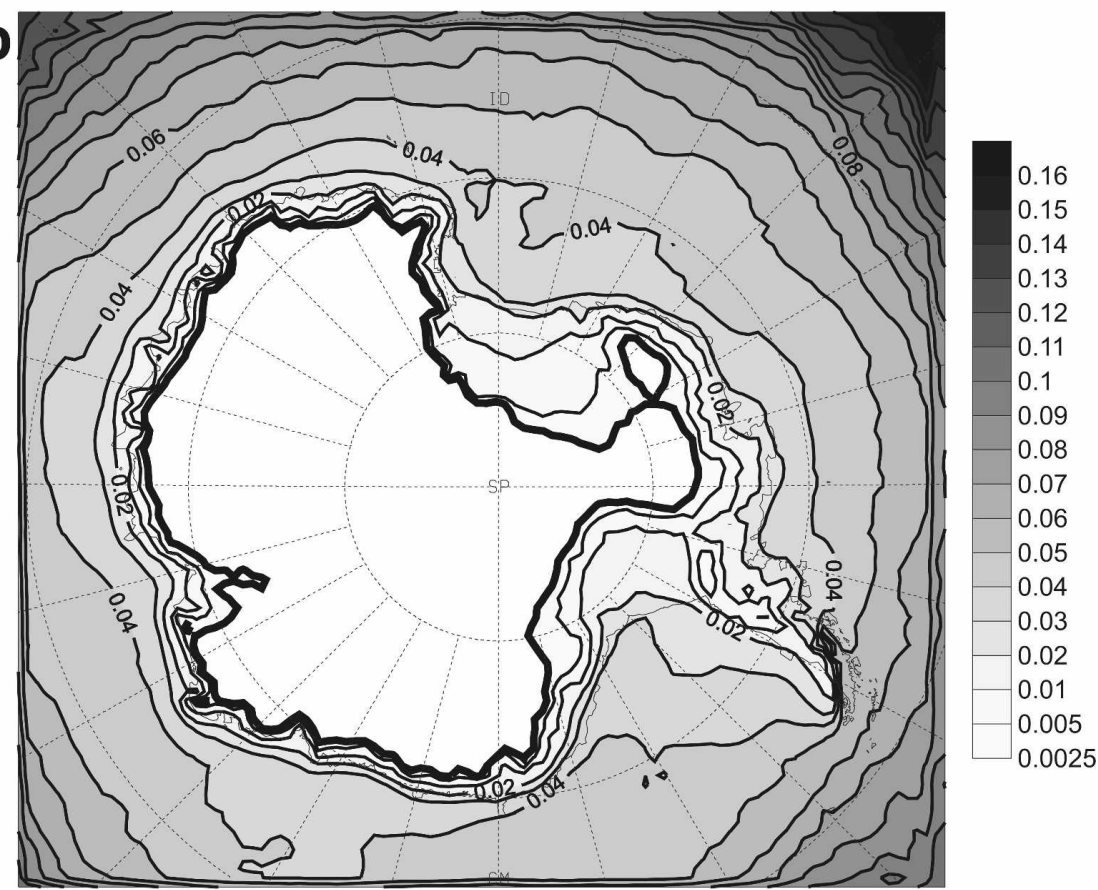

FIG. 11. Mean summer (Dec 2003-Feb 2004 and Dec 2004-Feb 2005) vertically integrated (a) cloud ice and (b) cloud liquid water, given that the 2-m relative humidity with respect to water is $>80 \%$. Contour interval is $0.005 \mathrm{~mm}$ in (a) and $0.01 \mathrm{~mm}$ in (b) above $0.01 \mathrm{~mm}$, with the $0.0025-\mathrm{mm}$ level thickened for reference in (b). not the CLWP. Therefore, deficient CLW does not necessarily lead to low modeled CF. Second, cloud cover (height and fraction) observations at McMurdo indicate that high clouds play a dominating role in the total $\mathrm{CF}$ amount, as cloud ceilings are reported at mid- and high (ice clouds in the pseudosatellite product) levels more than $50 \%$ of the time, and the remaining percentage of low cloud ceilings may often have high cloud cover not 
seen by manual observations. These combined effects suggest that although deficient model physics (shortage of cloud liquid water) clearly play a role in the underprediction of cloud seen in the original CF algorithm (and especially CF variability/correlation), the dominance of high clouds in determining the CF amount and the good prediction of these clouds by AMPS demonstrates that AMPS produces sufficient CICE. This consequently leads to an overall good agreement between the observed and modeled CFs in the modified algorithm, regardless of the presence or accuracy of the low-level cloudiness prediction.

Nonetheless, it is interesting that the small skill of low-level cloud prediction in the pseudosatellite product, and brings doubt upon the reliability of the microphysics scheme in AMPS in producing mixed-phase clouds. To understand this deficiency, Fig. 11 displays the summer average (averaged over the two summer seasons of 2003/04 and 2004/05) vertically integrated CICE (Fig. 11a) and CLW (Fig. 11b) in AMPS, the model variables upon which the pseudosatellite product is based. The averages are only calculated for cases when the 2-m relative humidity with respect to water is greater than or equal to $80 \%$ in order to provide a better estimate on the magnitude of these cloud microphysical quantities during cloudy conditions within the model. Independent tests (not shown) determine that clouds are present in satellite imagery based on this criterion more than $85 \%$ of the time except in the Ross Ice Shelf and West Antarctica regions, where the association drops to $75 \%$. Figure 11a demonstrates small concentrations of cloud ice over much of Antarctica, in agreement with known climatologies (e.g., Stone 1993), with the highest values of cloud ice found along the coast and the Antarctic Peninsula. Meanwhile, it is apparent that AMPS does not produce much cloud liquid water over the interior of the continent, as the 0.025 contour roughly follows the coast of Antarctica in Fig. $11 \mathrm{~b}$, and only extends to higher latitudes over the ice shelves and coastal West Antarctica. Despite the fact that summer near-surface temperatures can be warmer than $-34^{\circ} \mathrm{C}$ within the $0.025-\mathrm{mm}$ contour in Fig. $11 \mathrm{~b}$, the coldest temperature at which Beesley et al. (2000) demonstrated the presence of supercooled liquid water in the Arctic, AMPS rarely produces any liquid water over the interior of the continent. Morrison et al. (2003) demonstrate a similar problem in modeling the CLW in a single-column model in the Arctic. Compared with data from the Surface Heat Budget of the Arctic (SHEBA) project, they noted an underestimation of the CLW by $42 \%$, which was found to be sensitive to the ice crystal concentration. Other recent modeling studies in the Arctic compared with SHEBA data note similar deficiencies in modeling supercooled liquid water using the Reisner et al. (1998) scheme that is currently used in AMPS (Morrison and Pinto 2005, 2006; Morrison et al. 2005). Consequently, Morrison and Pinto (2006) find that a scheme that not only predicts mixing ratios of the hydrometeor species of cloud ice, cloud liquid water, rain, and snow within cloud layers [as in the Reisner et al. (1998) scheme], but also the number concentration of these species, is required to generate sufficient supercooled liquid water that is in better agreement with the observations. These studies help to explain the deficiency in low-cloud prediction by the pseudosatellite product as well as what changes are needed to predict the CLW variability and, therefore, likely improve the CF correlation.

\section{Summary and conclusions}

This paper has provided a detailed evaluation of the AMPS forecast atmospheric moisture and cloud characteristics. At both McMurdo and South Pole station, AMPS displays a positive relative humidity bias that increases with height up to $250-200 \mathrm{hPa}$, related to a weaker vertical decrease of moisture in AMPS compared with the observations. The bias is reduced at 100 $\mathrm{hPa}$, where both the model and observations have very low values of relative humidity. The correlation with the observations is greatest at McMurdo in the lower troposphere where more moisture is available, and greater at South Pole station in the upper troposphere to lower stratosphere, where both the model and observations show reduced variability in atmospheric moisture.

Cloud prediction by AMPS was evaluated using observations of CF at McMurdo and South Pole station and by comparing the pseudosatellite product, based on the microphysical quantities of cloud liquid water and cloud ice, with DMSP imagery. After adjusting the empirical CF algorithm to give more than twice as much weight to the CIWP, the CF error distribution is approximately centered on zero for both McMurdo and South Pole station, although the correlation is not improved and remains $\sim 0.4$. Nonetheless, the modified $\mathrm{CF}$ algorithm produces overcast conditions that better align with observations throughout all forecast hours at both sites. Validations of the pseudosatellite product demonstrate good skill in predicting high cloud cover. As high clouds are shown to dominate the total CF amount, they help to explain the strong agreement between the modeled and observed CF amounts. However, it was found that the microphysics scheme does not produce enough CLW over the interior of the continent, and that improvements in the variability of 
CLW in the microphysics scheme are needed to improve the CF correlation and prediction of low clouds in the pseudosatellite product. Notably, the accurate CICE variability and amount appears unrelated to the excessive model relative humidity near the tropopause, as even with these positive biases the model infrequently produces saturation with respect to ice above $500 \mathrm{hPa}$ (cf. Fig. 3c).

Nonetheless, it is apparent that the skill of cloud characteristics predicted by AMPS exceeds that of other similar atmospheric models. Hinkelman et al. (1999) find that the Eta Model has more inaccurately predicted clouds than correctly predicted clouds (based primarily on cloud height), as evaluated with observations at the Atmospheric Radiation Measurement (ARM) site in Oklahoma. In the Arctic, the greatest disagreement between eight different regional climate models was found in the predicted cloud cover, which led to errors in the surface radiation fluxes and 2-m temperature (Rinke et al. 2006) as evaluated with data from the SHEBA project. Hines et al. (2004) find similar errors in predicting Antarctic clouds within the NCAR climate models, especially noting that the clouds over the interior of the continent are too optically thick. Their study found that allowing for greater quantities of precipitate to fall out of the clouds produced better agreement between the observed wintertime temperatures and the downwelling shortwave radiation during summer. However, the validations presented here indicate that the cloud prediction by AMPS shows superior skill to these models, given that the temperature fields in AMPS are in good agreement with available observations (Bromwich et al. 2005), adjustments to the empirical $\mathrm{CF}$ algorithm produces nearzero bias at both McMurdo and South Pole station, and high cloud variability is captured well within the region and time period studied.

Future plans include a much more extensive evaluation of the pseudosatellite's performance, including the development of a product that uses the relative humidity fields to display modeled clouds, as well as further testing of AMPS cloud prediction performance using downwelling radiation measurements. Despite the known deficiencies, the pseudosatellite product currently serves as an important and powerful forecasting tool, as well as a potential research tool to better understand the climatology of clouds in an observationally sparse region. Given the high skill of the AMPS system displayed here with the modified CF algorithm and in high cloud prediction, it is likely that additional research that considers $\mathrm{CF}$ amount, high cloud variability, and moist processes in general can be conducted using AMPS. As such, model evaluations such as the one presented here not only serve the Antarctic forecasting community and AMPS users, but also the larger scientific community that uses AMPS archived forecasts to conduct climate studies across the Antarctic continent.

Acknowledgments. The authors thank Kathie Hill and Michael Town for discussions regarding cloud variability and observations at South Pole station, Daniel Steinhoff for processing and obtaining the satellite imagery for Figs. 9 and 10 from NASA's Level 1 Atmospheric Archive and Distribution System, and NSF for supporting the site visit by RLF to McMurdo and South Pole station in January 2006. This research was funded by UCAR Subcontract SO1-22961 and NSF Grant OPP-0337948.

\section{REFERENCES}

Beesley, J. A., C. S. Bretherton, C. Jakob, E. L. Andreas, J. M. Intrieri, and T. A. Uttal, 2000: A comparison of cloud and boundary layer variables in the ECMWF forecast model with observations at Surface Heat Budget of the Arctic Ocean (SHEBA) ice camp. J. Geophys. Res., 105, 12 337-12 349.

Bernhard, G., C. R. Booth, and J. C. Ehramjian, 2004: Version 2 data of the National Science Foundation's Ultraviolet Radiation Monitoring Network: South Pole. J. Geophys. Res., 109, D21207, doi:10.1029/2004JD004937.

Bromwich, D. H., R. I. Cullather, and R. W. Grumbine, 1999: An assessment of the NCEP operational Global Spectral Model forecasts and analyses for Antarctica during FROST. Wea. Forecasting, 14, 835-850.

—, J. J. Cassano, T. Klein, G. Heinemann, K. M. Hines, K. Steffen, and J. E. Box, 2001: Mesoscale modeling of katabatic winds over Greenland with the Polar MM5. Mon. Wea. Rev., 129, 2290-2309.

— A. A. Monaghan, J. G. Powers, and K. W. Manning, 2005: Real-time forecasting for the Antarctic: An evaluation of the Antarctic Mesoscale Prediction System (AMPS). Mon. Wea. Rev., 133, 579-603.

Cassano, J. J., J. E. Box, D. H. Bromwich, L. Li, and K. Steffen, 2001: Verification of Polar MM5 simulation of Greenland's atmospheric circulation. J. Geophys. Res., 106, 13 867-13 890.

Guo, Z., D. H. Bromwich, and J. J. Cassano, 2003: Evaluation of Polar MM5 simulations of Antarctic atmospheric circulation. Mon. Wea. Rev., 131, 384-411.

Hack, J. J., B. A. Boville, B. P. Briegleb, J. T. Kiehl, P. J. Racsh, and D. L. Williamson, 1993: Description of the NCAR Community Climate Model (CCM2). NCAR Tech. Note NCAR/ TN-382+STR, 108 pp.

Hines, K. M., D. H. Bromwich, P. J. Rasch, and M. J. Iacono, 2004: Antarctic clouds and radiation within the NCAR climate models. J. Climate, 17, 1198-1212.

Hinkelman, L. M., T. P. Ackerman, and R. T. Marchland, 1999: An evaluation of NCEP Eta Model predictions of surface energy budget and cloud properties by comparison with measured ARM data. J. Geophys. Res., 104, 19 535-19 549.

Hirvensalo, J., J. Währn, and H. Jauhiainen, 2003: New Vaisala RS92 GPS radiosonde offers high level of performance and GPS wind data availability. Preprints, 12th Symp. on Meteorological Observations and Instrumentation, Long Beach, 
CA, Amer. Meteor. Soc., 4.3. [Available online at http://ams. confex.com/ams/annual2003/techprogram/paper_55648.htm.]

Lachlan-Cope, T., R. Ladkin, J. Turner, and P. Davison, 2001: Observations of cloud and precipitation particles on the Avery Plateau, Antarctic Peninsula. Antarct. Sci., 13, 339-348.

Lubin, D., 1994: Infrared radiative properties of the maritime Antarctic atmosphere. J. Climate, 7, 121-140.

Mahesh, A., V. P. Walden, and S. G. Warren, 2001: Ground-based infrared remote sensing of cloud properties over the Antarctic Plateau. Part II: Cloud optical depths and particle sizes. $J$. Appl. Meteor., 40, 1279-1294.

Miloshevich, L. M., H. Vömel, A. Paukkunen, A. J. Heymsfield, and S. J. Oltmans, 2001: Characterization and correction of relative humidity measurements from Vaisala RS80-A radiosondes at cold temperatures. J. Atmos. Oceanic Technol., 18, 135-156.

— A. Aaukkunen, H. Vömel, and S. J. Oltmans, 2004: Development and validation of a time-lag correction for Vaisala radiosonde humidity measurements. J. Atmos. Oceanic Technol., 21, 1305-1327.

—, H. Vömel, D. N. Whiteman, B. M. Lesht, F. J. Schmidlin, and F. Russo, 2006: Absolute accuracy of water vapor measurements from six operational radiosonde types launched during AWEX-G and implications for AIRS validation. $J$. Geophys. Res., 111, D09S10, doi:10.1029/2005JD006083.

Monaghan, A. J., D. H. Bromwich, H. Wei, A. M. Cayette, J. G. Powers, Y. H. Kuo, and M. Lazzara, 2003: Performance of weather forecast models in the rescue of Dr. Ronald Shemenski from South Pole in April 2001. Wea. Forecasting, 18, 142-160.

,-- J. G. Powers, and K. W. Manning, 2005: The climate of the McMurdo, Antarctica, region as represented by one year of forecasts from the Antarctic Mesoscale Prediction System. J. Climate, 18, 1174-1189.

Morrison, H., and J. O. Pinto, 2005: Mesoscale modeling of springtime Arctic mixed-phase stratiform clouds using a new two-moment bulk microphysics scheme. J. Atmos. Sci., 62, 3683-3704.

— and - 2006: Intercomparison of bulk cloud microphysics schemes in mesoscale simulations of springtime Arctic mixed-phase stratiform clouds. Mon. Wea. Rev., 134, 18801900.

- M. D. Shupe, and J. A. Curry, 2003: Modeling clouds observed at SHEBA using a bulk microphysics parameterization implemented into a single-column model. J. Geophys. Res., 108, 4255, doi:10.1029/2002JD002229.
,-- M. D. Shupe, and P. Zuidema, 2005: A new doublemoment microphysics scheme for application in cloud and climate models. Part II: Single-column modeling of Arctic clouds. J. Atmos. Sci., 62, 1678-1693.

Murphy, A. H., 1996: The Finley affair: A signal event in the history of forecast verification. Wea. Forecasting, 11, 3-20.

Paukkunen, A., V. Antikainen, and H. Jauhiainen, 2001: Accuracy and performance of the new Vaisala RS90 radiosonde in operational use. Preprints, 11th Symp. on Meteorological Observations and Instrumentation, Albuquerque, NM, Amer. Meteor. Soc., 98-103.

Powers, J. G., A. J. Monaghan, A. M. Cayette, D. H. Bromwich, Y.-H. Kuo, and K. W. Manning, 2003: Real-time mesoscale modeling over Antarctica: The Antarctic Mesoscale Prediction System (AMPS). Bull. Amer. Meteor. Soc., 84, 15331545.

Reisner, J., R. M. Rasmussen, and R. T. Bruintjes, 1998: Explicit forecasting of supercooled liquid water in winter storms using the MM5 forecast model. Quart. J. Roy. Meteor. Soc., 124, 1071-1107.

Rinke, A., and Coauthors, 2006: Evaluation of an ensemble of Arctic regional climate models: Spatiotemporal fields during the SHEBA year. Climate Dyn., 26, 459-472.

Stone, R. S., 1993: Properties of austral winter clouds derived from radiometric profiles at the South-Pole. J. Geophys. Res., 98, 12 961-12 971.

Town, M. S., V. P. Walden, and S. G. Warren, 2005: Spectral and broadband longwave downwelling radiative fluxes, cloud radiative forcing, and fractional cloud cover over the South Pole. J. Climate, 18, 4235-4252.

,-- and -2007 : Cloud cover over the South Pole from visual observations, satellite retrievals, and surface-based infrared radiation measurements. J. Climate, 20, 544-559.

Turner, J., and S. Pendlebury, Eds., cited 2007: The international Antarctic forecasting handbook. Bureau of Meteorology, Melbourne, VIC, Australia. [Available online at http://www. bom.gov.au/weather/ant/handbook/handbook_16june04. pdf.]

Vukicevic, T., T. Greenwald, M. Zupanski, D. Zupanski, T. Vonder Haar, and A. S. Jones, 2004: Mesoscale cloud state estimation from visible and infrared satellite radiances. Mon. Wea. Rev., 132, 3066-3077.

Wilks, D. S., 2006: Statistical Methods in the Atmospheric Sciences. Academic Press, 630 pp. 